\title{
Algo sobre El ethos, destino del hombre
}

\author{
Josu Landa
}

E

n su Autobiografía, Bertrand Russell revela que "tres pasiones, simples pero abrumadoramente fuertes, han gobernado mi vida: el deseo de vivir, la busca del conocimiento y la insoportable piedad por el sufrimiento de la humanidad". ${ }^{1}$ Si se suavizara el tono un tanto patético de la última parte de esta confesión de lord Russell -algo bastante extraño en él, por cierto-, es seguro que Juliana González la suscribiría sin inconvenientes. También ella ha hecho de la vida su principal divisa, ha perseguido y persigue el saber con denuedo no carente de tino, y no ha cejado nunca en su larga batalla personal contra el sufrimiento humano.

Con la publicación de El malestar en la moral, en 1986, Juliana González empezó a mostrar los alcances de una extensa relación de su peculiar descenso a los infiernos del alma humana. $E l$ ethos, destino del hombre es un nuevo momento en esa relación, que incluye otros dos libros: Ética y libertad (1989) y El héroe en el alma. Tres ensayos sobre Nietzsche (1993), además de numeros textos aparecidos en diversas publicaciones de México y del extranjero. Desde luego, Juliana González no habría podido emprender ese viaje de resonancias a su manera órficas, si no hubiera contado con el poderoso viático de La metafísica dialéctica de Eduardo Nicol (1981).

El ethos, destino del hombre es un libro unitario, aunque dividido realmente en tres secciones: la que reúne sendas reflexiones de Juliana González sobre ética y humanismo y sobre valor y ser, el estupendo ramillete de ensayos sobre ética aplicada y, al final, la serie de tres trabajos exegéticos agrupados bajo el rótulo de "Ethos y anthropos". Un simple vistazo a dichos escritos basta para apreciar una de sus virtudes: la brevedad; y si los textos son breves es porque abordan con precisión estimable los temas del caso.

${ }^{1}$ Citado en Lo mejor de Bertrand Russell, selec. e introd. de Robert E. Egner, trad. de Marco Aurelio Galmarini. Barcelona, EDHASA, 1989, p. 145. 
Los contenidos que fluyen en este último libro de Juliana González dan cuenta de un haz de supuestos y tesis capitales, al que me referiré inmediatamente:

- La ontología y la ética son indisociables; se requieren recíprocamente: no es posible una rigurosa teoría del ethos sin una teoría del ser, en general, y del ser humano, en particular. Tampoco tiene sentido "pensar el ser en cuanto ser", sin mirar las implicaciones morales que ello comporte.

- La realidad humana es natural y cultural a la vez. Las determinaciones naturales más primarias no eximen a los seres humanos de la tarea de conformar una "segunda naturaleza" (precisamente, el ethos). Tan ontológica y necesaria es una como otra. Esto es lo que explica que el ethos sea "el destino del hombre”, como lo advierte el título heraclíteo del libro de Juliana González.

- Lo esencialmente humano no excluye el devenir, el tiempo, la historia, sino que lo exige. El ser humano y el ethos que realiza y en el que se realiza se sostienen en una base de permanencia universal, a la par de que despliegan su existencia sobre la plataforma de la historia. Así, la diferencia está en la raíz de la identidad del ser humano y viceversa. Esta idea se complementa, además, con la tesis de estirpe existencialista de que el hombre es posibilidad, proyecto, más que una entidad fundada en una esencia universal e inmutable.

- La fundamentación ontológica de la ética evita de raíz la posibilidad del solipsismo. No existe subjetividad que no remita a una alteridad, sea esta natural o social. No hay yo que no se constituya a partir de una referencia necesaria al otro. No sólo se trata de "la incurable otredad que en nosotros padece lo uno para el caso de que no hubiera más alma que la nuestra”, como enseñaba Juan de Mairena. ${ }^{2}$ Es también la idea que expresa con justa contundencia la propia Juliana González, cuando afirma que el hombre es un “'estado' erótico de deseo del otro, de movimiento hacia el otro y hacia el lleno de su ser; es, en última instancia, radical deseo de ser". ${ }^{3}$

- Asimismo, la consideración de las bases ontológicas de los valores comporta una refutación de todo relativismo moral fuerte. Juliana González acepta la historicidad de los valores y está consciente de las determinaciones sociales o de otra índole que puedan obrar de diversos modos sobre ellos. Lo que no admite es la irresponsable consigna de que todo vale por igual. Contra toda postura que se desentienda de la verdad y la veracidad que sostengan a los actos humanos, contra la falsa prédica de que no hay criterios fiables de valoración, Juliana González declara sin ambages: "Es falso que no haya criterios de valor:

${ }^{2}$ Antonio Machado, Juan de Mairena. Sentencias, donaires, apuntes y recuerdos de un profesor apócrifo, ed., pról., y estudio comparativo de Pablo Barco. Madrid, Alianza, 1981.

${ }^{3}$ Juliana González, El ethos, destino del hombre. México, UNAM/FCE, 1996, pp. 5657. 
éstos se encuentran en un consenso y una tradición históricos que tienen alcance ético y ontológico". ${ }^{4}$ Tesis que, por lo demás, refuerza con su idea de los "signos de valor" objetivos, aunada a la imagen socrática del daimon ("la voz que pronuncia el 'sí' y el 'no' del mundo del valor". 5

- El ethos impulsa al hombre a una permanente humanización de sí mismo y de su entorno natural, político y moral. En el núcleo de este libro de Juliana González sobresale eso que Ernst Bloch denominó "principio esperanza". En virtud de ese principio - pese a que no se podría hablar en rigor de "progreso"afloran y se establecen en el mundo las referencias de una vida cultural y moralmente superior.

- Contra una moralidad cimentada en el terror, los preceptos religiosos o la simple inercia alienante de un orden de usos, prohibiciones jurídicas, etcétera, Juliana González propone una ética autónoma, vale decir una ética racional. Ahora bien, esta propuesta no subestima el potencial ético y axiológico de los apetitos y las pasiones. Al contrario, considera que la compleja realidad del deseo está en la base de la humanísima inclinación a valorar, es decir, de eso que Savater ha llamado "voluntad de valor". Sin embargo, esta proclividad espontánea a estimar y preferir lo mejor puede y debe orientarse hacia una autosuficiencia en la valoración y una autorregulación en la acción.

Esta recensión de los filosofemas que alberga $\mathrm{El}$ ethos, destino del hombre sería incompleta, si omitiera cuatro principios con los que se identifica Juliana González: el respeto incondicional y total a la vida, el reconocimiento de la problemática libertad del hombre, la consideración del ser humano como un fin (no como un medio) y la tolerancia ante lo diferente.

Voy a decir una obviedad, con toda "intención": este es un libro de filosofía práctica. Es, ante todo, una lección de filosofía, sólo que versa sobre nuestra realidad moral. En otras palabras, se trata de un texto donde toma forma un modo de hacer filosofía. ¿En qué consiste su peculiaridad? Básicamente en dos rasgos poco frecuentes en nuestro medio: es consecuente con el ideal de sapere aude (atreverse a pensar), a partir de un compromiso incondicional con la verdad, y aspira a dar respuestas viables a problemas y exigencias éticas del presente. No es, pues, un compendio de comentarios de comentarios (aunque Juliana González no rehuya la interpretación, siempre que se avenga con su trabajo de pensar con criterio propio). Tampoco una summula estéril de ejercicios teoréticos ajenos a nuestras vidas. $E l$ ethos, destino del hombre logra un equilibrio entre especulación y praxis; es decir, conjuga las intuiciones más radicales ("radical" es el adjetivo que con mayor frecuencia usa Juliana González) con prescripciones aptas para orientar la acción. Los textos "Ética y humanis-

\footnotetext{
${ }^{4}$ Ibid., p. 64.

${ }^{5}$ Ibid., p. 74 .
} 
mo" y "Valor y ser" son un ejemplo consumado de las primeras, los que se refieren al suicidio, a la pena de muerte, a la medicina y a la ética profesional lo son de las segundas.

Desde que la filosofía se interesa por el hombre, además de por la naturaleza y el logos, el pensar no puede soslayar temas como el bien obrar, el buen vivir, el bien decir y afines. Para expresarlo con palabras de Foucault, la filosofía es asumida como amor a una sabiduría que orienta al hombre en sus necesarias "prácticas de sí mismo". ${ }^{6}$ Ética, política, poética, retórica y eudemonología son los afluentes de un río de pensamiento que no puede conformarse con la teoría pura, aunque siempre la exija y la ponga en primer plano, en tanto que es "filosofía primera". Sócrates es el artífice principal de esta mutación en la historia de la filosofía, aunque cuente con antecedentes notables como Heráclito y el pitagorismo. Platón y Aristóteles concretarán al máximo sus posibilidades. La persistente labor filosófica de Juliana González abreva en esta tradición y la enriquece. Tradición en la que habría que contar, pese a las diferencias entre sí, a Spinoza, Kant, Hegel, Schopenhauer, Nietzsche, Heidegger, Sartre, Nicol, Foucault y otros pensadores con los que dialoga críticamente Juliana González, muchas veces echando mano de autores altamente sugerentes por sus nexos tan intensos con el pensamiento: Dostoyevski, Freud, Kafka, Camus, Paz, etcétera.

En el eterno retorno de nacimiento y muerte, bien y mal, vitalidad y agonía, construcción y destrucción, alegría y sufrimiento, azar y necesidad... que es el mundo, la tarea de ser humano es todo, menos fácil. De hecho, sería una misión imposible, si los caminos que nos llevan a nosotros mismos, pasando por los otros y las cosas del mundo, estuvieran rotos u obturados. Es decir, si se nos hubieran negado los dones de la sensibilidad, el lenguaje, el deseo, la razón, la poesía, el saber, el sentido... Somos seres en relación, de relación y por relación; y en el frágil suelo de este hecho se cifran nuestras venturas y desdichas. Hay quienes legítimamente afrontan esta condición de la humanidad, recurriendo a la protección de un dios o abrazando algún fundamentalismo religioso o tribal. Desde luego, no faltan quienes con igual licitud concuerdan con Lichtenberg en la creencia de que "el mejor refugio contra las tormentas del destino sigue siendo una tumba". ${ }^{7}$ Sin embargo, hay por lo menos otra posibilidad: una ética autónoma, en virtud de la cual el hombre se da la ley a sí mismo y la re-crea constantemente, desechando dogmas, así como decálogos

${ }^{6}$ Michel Foucault, "La ética del cuidado de uno mismo como práctica de la libertad", en Hermenéutica del sujeto, ed. y trad. de Fernando Álvarez-Uría. Madrid, La Piqueta, 1994.

${ }^{7}$ Georg Christoph Lichtenberg, Aforismos, selec., trad., pról. y notas de Juan Villoro. México, FCE, 1989. 
pretendidamente universales y tradiciones tenidas por inmutables. Una ética, en fin, que apuesta por la vida y contra todas las formas del sufrimiento, apelando a una sabiduría que busca armonizar la conciencia (no exenta de cierta dosis de sana soberbia) de los poderes de la razón con la certeza (preñada de humildad) de sus límites y flaquezas. Esta es la opción que con plena honestidad ofrece Juliana González, en este libro y en toda su obra filosófica, a los hombres y mujeres de buena voluntad. 